\title{
Spatial distribution of soil organic carbon stocks in France
}

\author{
M. P. Martin ${ }^{1}$, M. Wattenbach ${ }^{2}$, P. Smith ${ }^{3}$, J. Meersmans ${ }^{1}$, C. Jolivet ${ }^{1}$, L. Boulonne ${ }^{1}$, and D. Arrouays ${ }^{1}$ \\ ${ }^{1}$ INRA Orléans, InfoSol Unit, US 1106, CS 40001, Ardon, 45075, Orléans cedex 2, France \\ ${ }^{2}$ Freie Universität Berlin, Institute of Meteorology, Carl-Heinrich-Becker-Weg 6-10, 12165 Berlin, Germany \\ ${ }^{3}$ Institute of Biological \& Environmental Sciences, University of Aberdeen, Cruickshank Building, St. Machar Drive, \\ Aberdeen, AB24 3UU Scotland, UK
}

Received: 8 September 2010 - Published in Biogeosciences Discuss.: 18 November 2010

Revised: 10 February 2011 - Accepted: 1 April 2011 - Published: 4 May 2011

\begin{abstract}
Soil organic carbon plays a major role in the global carbon budget, and can act as a source or a sink of atmospheric carbon, thereby possibly influencing the course of climate change. Changes in soil organic carbon (SOC) stocks are now taken into account in international negotiations regarding climate change. Consequently, developing sampling schemes and models for estimating the spatial distribution of SOC stocks is a priority. The French soil monitoring network has been established on a $16 \mathrm{~km} \times 16 \mathrm{~km}$ grid and the first sampling campaign has recently been completed, providing around 2200 measurements of stocks of soil organic carbon, obtained through an in situ composite sampling, uniformly distributed over the French territory.

We calibrated a boosted regression tree model on the observed stocks, modelling SOC stocks as a function of other variables such as climatic parameters, vegetation net primary productivity, soil properties and land use. The calibrated model was evaluated through cross-validation and eventually used for estimating SOC stocks for mainland France. Two other models were calibrated on forest and agricultural soils separately, in order to assess more precisely the influence of pedo-climatic variables on SOC for such soils.

The boosted regression tree model showed good predictive ability, and enabled quantification of relationships between SOC stocks and pedo-climatic variables (plus their interactions) over the French territory. These relationships strongly depended on the land use, and more specifically, differed between forest soils and cultivated soil. The total estimate of SOC stocks in France was $3.260 \pm 0.872 \mathrm{PgC}$ for the first $30 \mathrm{~cm}$. It was compared to another estimate, based on the
\end{abstract}

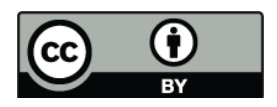

Correspondence to: M. P. Martin (manuel.martin@orleans.inra.fr) previously published European soil organic carbon and bulk density maps, of $5.303 \mathrm{PgC}$. We demonstrate that the present estimate might better represent the actual SOC stock distributions of France, and consequently that the previously published approach at the European level greatly overestimates SOC stocks.

\section{Introduction}

The increasing concentration of greenhouse gases in the atmosphere has led to the need for reliable estimates of the amounts of organic carbon that might be sequestered by soils (Batjes, 1996; Eswaran et al., 1993; Lal, 2004; Paustian et al., 1997; Post et al., 1982; Saby et al., 2008a; Schlesinger, 1991).

Indeed, the organic matter contained in the earth's soils is a large reservoir of carbon (C) that can act as a sink or source of atmospheric $\mathrm{CO}_{2}$. The world's soils represent a large reservoir of $\mathrm{C}$ of about $1500 \mathrm{PgC}$ (Batjes, 1996; Eswaran et al., 1993; Post et al., 1982). Accurate estimates of this pool are needed. However their reliability depends upon suitable data in terms of organic carbon content and soil bulk density and on the methods used to upscale point data to comprehensive spatial estimates. There are, therefore, few precise assessments of soil organic carbon (SOC) stocks based on measurements over large areas since systematic sampling schemes including SOC, bulk density and rock fragment content are quite rare (Morvan et al., 2008), and because high spatial variability of SOC requires a very high sampling density to get accurate estimates (Bellamy et al., 2005; Saby et al., 2008b). Several approaches involving empirical models to upscale SOC point measurements to the national level are found in the literature. These approaches range from

Published by Copernicus Publications on behalf of the European Geosciences Union. 
simple statistics or pedotransfer rules, relating SOC contents or stocks to soil type (Yu et al., 2007) or soil type and land use (Tomlinson and Milne, 2006; Arrouays et al., 2001), to multivariate statistical models (Meersmans et al., 2008, with multiple linear models and Yang et al., 2008, with generalized linear models). Recent studies have used techniques adapted from the data mining and machine learning literature, with piecewise linear tree models (Bui et al., 2009) or multiple regression trees for regional studies (Grimm et al., 2008; Lo Seen et al., 2010). Despite the spatial dimension of such studies, few geostatistical approaches have been proposed for use at the national scale (but see Chaplot et al., 2009), mainly because of the difficulty of including the effect of the different drivers of SOC dynamics in geostatistical models.

Jones et al. (2005) developed a methodology for estimating organic carbon concentrations (\%) in topsoils (octop) across Europe and recently published a map of SOC stocks by country. The information is available as a database which can be downloaded from the EU-soils web site (http: //eusoils.jrc.it). This methodology, based on pedotransfer functions, gave results which were validated using data from England and Wales and Italy (Jones et al., 2005). However, the match between country level estimates of SOC stocks using this method and estimates based on national databases depends on the country and may sometimes be poor. For instance, SOC stocks for the first $1 \mathrm{~m}$ in Denmark was estimated to vary from 0.563 to $0.598 \mathrm{PgC}$, among which $60 \%$ is found in the $0-28 \mathrm{~cm}$ layer (Krogh et al., 2003). Thus, the amount can be rescaled to 0.338 to $0.359 \mathrm{PgC}$, for the first $28 \mathrm{~cm}$ layer, compared to the Joint Research Center (JRC)'s estimate of $0.6 \mathrm{PgC}$ for only the first $30 \mathrm{~cm}$ (Hiederer, 2010). The issue of accurately assessing SOC stocks at the country level is critical, because SOC stocks are used as input for studies on the impact of future land use change or climate change on SOC stocks dynamics, and on potential greenhouse gases (GHG) emissions (Chaplot et al., 2009). For instance, they may be used for defining the baseline state for SOC change simulations (van Wesemael et al., 2010), or setting some of the models' parameters (Tornquist et al., 2009). In this paper, we apply a new methodology: boosted regression trees (BRT), already successfully applied in India (Lo Seen et al., 2010), to predict the geographical distribution of SOC stocks in metropolitan France from a set of 1974 paired observations of SOC and bulk densities. We examine the effects of the main controlling factors of SOC stocks distribution. We estimate the uncertainty of our national estimate and compare the results with those previously obtained by Arrouays et al. (2001) and Hiederer (2010) on the same territory.

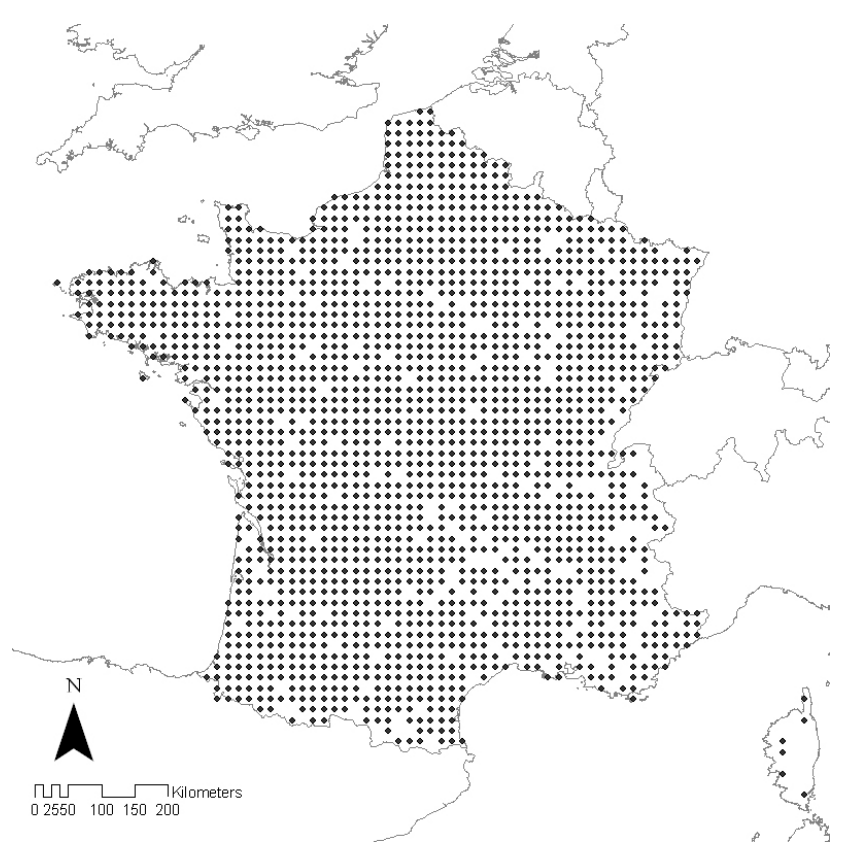

Fig. 1. Distribution of the 1974 sites within the French monitoring network which were used in the present study.

\section{Materials and methods}

\subsection{Data}

\subsubsection{Site specific soil and agricultural data}

Soil Organic Carbon Stocks were computed for a subset of 1974 sites from the French soil survey network (RMQS), for which analytical data was available (Fig. 1). This dataset covered a broad spectrum of climatic, soil and agricultural conditions. In the near future, the RMQS will cover the entire metropolitan France. The network is based on a $16 \mathrm{~km} \times 16 \mathrm{~km}$ square grid and the sites are selected at the centre of each grid cell resulting in about 2200 soil sampling sites. In the case of soil being inaccessible at the centre of the cell (i.e. urban area, road, river, etc.), an alternative location with a natural (undisturbed or cultivated) soil is selected as close as possible, but within $1 \mathrm{~km}$ from the centre of the cell (for more information, see Arrouays et al., 2002).

At each site, 25 individual core samples were taken from the topsoil $(0-30 \mathrm{~cm})$ using a hand auger according to a stratified random sampling design within a $20 \mathrm{~m} \times 20 \mathrm{~m}$ area. Individual samples were mixed to obtain a composite sample for each soil layer. Apart from composite sampling, at $5 \mathrm{~m}$ from the south border of the $20 \mathrm{~m} \times 20 \mathrm{~m}$ area, a soil pit was dug, from which main soil characteristics were described and 6 bulk density measurements were done, as described previously (Martin et al., 2009). From these data, SOC stocks were computed for the $0-30 \mathrm{~cm}$ soil layer. 
SOCstocks $_{30 \mathrm{~cm}}=\sum_{i=1}^{n} p_{i} \mathrm{BD}_{i} \operatorname{SOC}_{i}\left(1-r f_{i}\right)$

where $n$ is the number of soil horizon present in the $0-30 \mathrm{~cm}$ layer, $\mathrm{BD}_{i}, r f_{i}$ and $\mathrm{SOC}_{i}$ the bulk density, percentage of rock fragments (relative to the mass of soil) and the SOC concentration (percent) in these horizons, and $p_{i}$ the fraction of the horizons to take into account to reach the $30 \mathrm{~cm}$.

Field observations were used to assign land use category values to the RMQS sites. Land cover was described using a 3 level classification, similar to the procedure used for the Corine Land Cover maps (Feranec et al., 2010). Level 1 (L1) land covers include various crops (1), permanent grasslands (2), woodlands (3) orchards and vineyards, shrubby perennial crops (4), wasteland (5), specific natural systems (6) and parks and gardens (7). Levels 2 and 3 refine level 1. For instance, for specific woody surfaces, one could find the following description: woody surface (L1), forest (L2) and coniferous forest (L3). The number of classes were 7, 22 and 41 for the L1, L2 and L3 levels, respectively.

Soil moisture regime was also described using two variables wlogging and wregime, which were used as predictors for SOC stocks. wregime indicates soil moisture regime resulting from field observations (by soil scientists). It is described according to 6 classes, depending on the degree of saturation and its timing: "permanently saturated", "saturated every day", "saturated for some part of the year", "continuously moist", "dry for some part of the year", "continuously dry". wlogging describes the origin of waterlogging (perched water table, groundwater, springs and resurgences, submersion), according to field observations.

\subsubsection{Net Primary Productivity data}

The Moderate Resolution Imaging Spectroradiometer Net Primary Productivity (http://modis.gsfc.nasa.gov/ MODIS NPP, $\mathrm{gC} \mathrm{m}^{-2} \mathrm{yr}^{-1}$ ) was used to get NPP estimates at each of the RMQS sites. MODIS NPP data are made of $926 \times 926 \mathrm{~m}^{2}$ resolution raster images. The MODIS algorithm uses the near-infrared wavelength to estimate the normalized difference vegetation index (NDVI), used in turn to estimate the daily gross primary production, the daily net photosynthesis and finally the annual net primary productivity. The estimation involves constants depending on the vegetation type, such as the active radiation conversion efficiency coefficient (Running et al., 2004). Thus the MODIS NPP data are to be used with corresponding MODIS land cover raster images, since the NPP estimate depends on the vegetation type. The method for estimating an NPP value at the RMQS sites consisted of a three step procedure. For each RMQS site, first, pixels from the MODIS layer not matching the land use of the RMQS site where excluded. Second, mean and standard deviation of NPP values of pixels with matching land cover (i.e. not hidden in the previous step) and not further than a limit distance $\left(d_{\lim }\right)$ were computed. Four $d_{\text {lim }}$ were tested, in $\{5,10,20,30\} \mathrm{km}$. Third, $d_{\text {lim }}$ resulting in the highest mean/standard deviation of NPP values was selected. The estimate of NPP at the RMQS site was the mean of MODIS NPP values for the selected $d_{\text {lim }}$. Prior to applying this procedure, MODIS land covers were reclassified to match the RMQS land cover classification (L1).

\subsubsection{Climatic data}

Available climatic data were monthly precipitation $\left(\mathrm{mm} \mathrm{month}^{-1}\right)$, potential evapotranspiration (PET, mm month $\left.{ }^{-1}\right)$, and temperature $\left({ }^{\circ} \mathrm{C}\right)$ at each node of a $12 \times 12 \mathrm{~km}^{2}$ grid, averaged for the 1992-2004 period. These climatic data were obtained by interpolating observational data using the SAFRAN model (Quintana-Segui et al., 2008), which was initially designed for providing an analysis of the atmospheric forcing in mountainous areas for avalanche forecasting. The RMQS site specific data were linked to the climatic data by finding for each RMQS site the closest node within the $12 \times 12 \mathrm{~km}^{2}$ climatic grid. This grid was also used in turn as climatic data input when applying the BRT model to the whole territory. Elaborated agro-pedo-climatic variables were also derived from the rough data: we used temperature and soil moisture mineralization modifiers, as modelled in the RothC model (Coleman et al., 1997). The mineralization modifier related to temperature $(a)$ was estimated directly from temperature data from the $12 \times 12 \mathrm{~km}^{2}$ climatic grid. The mineralization modifier related to soil moisture ( $b$, function of clay, land use and climatic data) was estimated differently for point data (observations at the RMQS site) and the continuous spatial layers used for interpolation. For point data, we combined rainfall and PET data obtained from the climatic grid, with site observation of land use and clay content. Continuous spatial layers of $b$ were obtained by combining the climatic grid, the spatial layers for land use and clay content (see Sect. 2.2). $b$ was then calculated within each homogeneous spatial unit regarding climate, land use and clay content. The RothC modelling of the influence of water content, $b$, onto the mineralization of SOC is applicable for soils that are both non-waterlogged soils (Coleman et al., 1997) and not organic organic (Yokozawa et al., 2010). We did not check for the first criteria since the use of other predictors such as wlogging and wregime gave the possibility to the statistical model to minimize the influence of $b$ for specific values of wlogging or wregime where the RothC modeling would not have been relevant. Regarding the second criteria, following the World Reference Base system, organic soils (histosols) are characterized by organic matter contents above $30 \%$ for the first $30 \mathrm{~cm}$ (ISSS-ISRIC-FAO, 1998). Our dataset contained only 1 such soil. Hence we did not make specific treatment for this single individual, taking into account the robustness to the presence of outliers in the dataset, in the statistical models used in this study. 


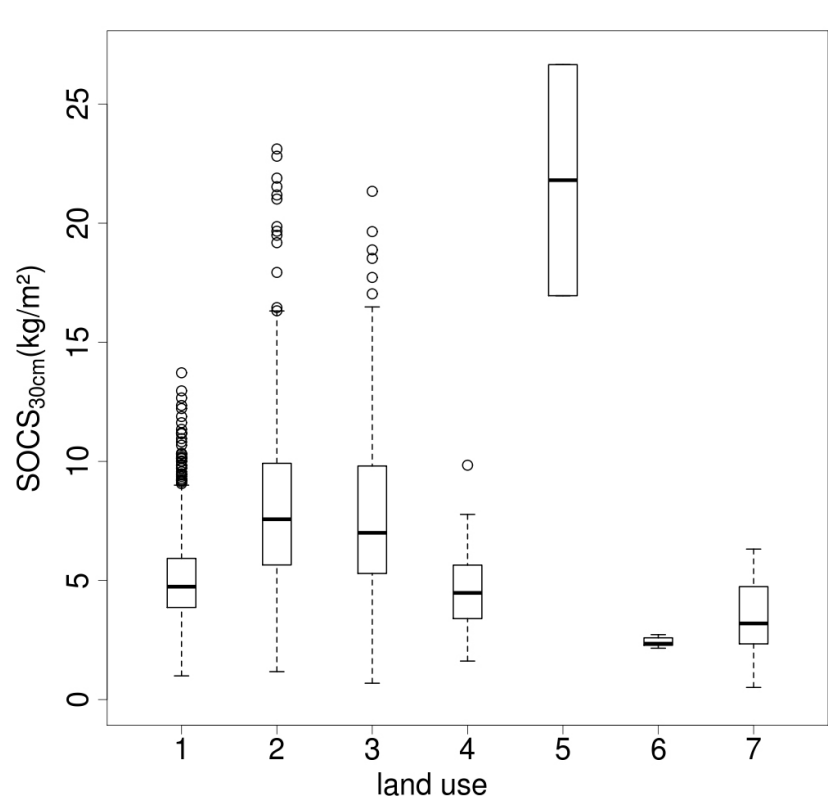

Fig. 2. SOC stocks for the first $30 \mathrm{~cm}$ as a function of land cover type according to the adapted IPCC land use classification (various crops $(1, n=817)$, permanent grasslands $(2, n=463)$, woodlands ( $3, n=468)$ orchards and shrubby perennial crops $(4, n=18)$, wetlands $(5, n=2)$, others $(6, n=5)$, vineyards $(7, n=32))$.

\subsection{Spatial layers used for interpolation}

Soil spatial coverage was obtained from the 1/1000 $000 \mathrm{Eu}-$ ropean soil map. Land use data was taken from the TERUTI (Utilisation du Territoire) survey (Chakir and Parent, 2009) provided by the statistical center of the ministry of agriculture (SCEES). This survey comprises 150000 observational locations where the land use is recorded. The same locations were surveyed yearly between 1992-2004 to determine the land cover and the land use. The survey provides with instant distribution of the land uses as well as temporal transitional data from one land use to another. The 2004 recordings of land use distribution were used for estimating the SOC stocks distribution. Prior to this, TERUTI data have been reclassified to match a classification adapted from the Intergovernmental Panel on Climate Change (IPCC) reporting guidelines (see legend of Fig. 2).

\subsection{Boosted Regression Trees (BRT) Modelling}

Boosted regression trees belong to the Gradient Boosting Modelling (GBM) family. GBM is one among many methods to solve the predictive learning problem where the objective is to estimate the function $F$ that maps the values of a set of predictor variables $x=\{x 1, \ldots, x p\}$ into the values of the output variable $y$, by minimizing a specified loss function $L$. It uses one particular approach to prediction, i.e. classification and regression trees (Breiman et al., 1984), that is extended using a powerful learning technique called boost- ing (Freund and Schapire, 1996). Boosting methods are generally applied to significantly improve the performance of a given estimation method, by generating instances of the method iteratively from a training data set and additively combining them in a forward "stagewise" procedure. BRT uses a specialized form (for regression trees) of the Stochastic Gradient Boosting (Friedman, 2001). A thorough description of the method is given in Friedman (2001) and a practical guide for using it in Elith et al. (2008).

BRT is known to have improved accuracy compared with simple regression trees, thanks to its stochastic gradient boosting procedure aiming at minimizing the risk of overfitting and improving its predictive power (Lawrence et al., 2004). The algorithm enabling fitting the model to the data is an iterative process. At each iteration, individual regression trees, which will compose the final BRT model, are fitted on a fraction (namely the bag fraction) of the dataset sampled without replacement. The main parameters for fitting BRT (boosted regression trees) are the learning rate and the tree size, also known as interaction depth. The learning rate $(l r)$, sometimes called shrinkage parameter, is the constant coefficient determining the influence of the individual trees combination that forms the final BRT model. The second important parameter is the tree size $(t s)$. It gives the size of individual regression trees. When $t s$ is one, each individual tree is made of a single node, thus modeling the effect of only one predictor variable. Then, the final additive model separately includes the effects of the predictor variables and the interactions between variables are not explicitly taken into account. When $t s=i$ and is strictly greater than one, each individual tree models the interaction of at least two predictor variables. This enables the use of models taking into account $i$-th order interactions between predictor variables. The ability to represent interactions between predictor variables without a priori knowledge is one of the advantages of BRT and more generally of regression trees. Two other important parameters are the minimum number of observations in the terminal leaves of the trees (min.obs) and the bag fraction ( $b f$ ).

The contribution of predictor variables are assessed using a variable importance index (VIM), based on the number of times a given variable is selected for splitting individual trees weighted by the square improvement to the model as a result of these trees, summed over all the individual trees (Friedman and Meulman, 2003).

The nature of the dependence between the predictors and the response variable can be assessed by using average or partial dependence plots (Hastie et al., 2001). Put it briefly, they represent the effect of a set of selected predictors (usually 1 to 3 ) on the modelled response variable after accounting for the effects or the remaining (not selected) predictors. 
The BRT models were fitted and used for prediction using the "gbm" R package (Ridgeway, 2006). The stopping criterion for choosing the best iteration when fitting a BRT model was the cross validation method under "gbm" (with cross-validation folds set to 5), since this method was shown to be the most efficient one (Ridgeway, 2006) amongst the ones available in the "gbm" package. In this study, whatever the BRT parameters' value, the maximum number of allowed iterations was set so that the choice of the model's best iteration did not depend on it. We undertook a tuning procedure for identifying the best combination of these parameters as in Martin et al. (2009).

\subsubsection{Models of SOC stocks}

Three models of SOC stocks were tested, for prediction on the $0-30 \mathrm{~cm}$ layer. Two models using all available predictors, among which one aimed at explaining SOC values on forest lands ( $\mathrm{F}$ model), and the other one in cultivated areas (Cult model). The third model used only predictors available at the national scale and was applied to prediction at this scale. This model was fitted on the $0-30 \mathrm{~cm}$ stocks making up one additional model used for interpolation (Extra model).

The F model was fitted on sites under forest (421 sites) and the Cult model on cultivated sites (1398 sites) only. This was done in order to facilitate models results interpretation and also because SOC stocks variability is known for being much more important in forest lands compared to cultivated land (Saby et al., 2008b).

The predictors used for each model were:

- the Cult model: lu1, lu2 and lu3 (land use coded according to, respectively, the L1, L2 and L3 RMQS land cover classifications), clay (\%), silt (\%), rf (rock fragments, mass percentage), potential evapotranspiration (pet, mm month ${ }^{-1}$ ), monthly precipitation (rain, mm month $\left.{ }^{-1}\right)$, temperature $\left(\right.$ temp, $\left.{ }^{\circ} \mathrm{C}\right)$, ph, wregime (water regime), wlogging (water-logging), the two RothC mineralization modifiers, $a$ and $b$ and the net primary productivity $n p p\left(\mathrm{gC} \mathrm{m}^{-2} \mathrm{yr}^{-1}\right)$.

- the F model shared the same set of predictors except for lul which was excluded since it exhibited only one level for forests.

- the Extra model: lu_ipcc (land use classification adapted from the IPCC guidelines, 2006), clay, pet, rain, temp, $a, b$ and $n p p$.

\subsubsection{Validation procedure}

The BRT models were validated in two ways. The first procedure involved fitting the models to the full dataset (with a restriction regarding the land use for the Cult and F models) and validating model predictions on this dataset. The second involved using cross-validation. The first procedure enabled to estimate the quality of the fit of the models of $\mathrm{C}$ prediction. Only the second validation procedure, which involved validation against independent data, enables to estimate the predictive power of the proposed models.

In both procedures, comparison between observed and predicted values of SOC stocks was carried out using several complementary indices, as is commonly suggested (Schnebelen et al., 2004): the mean prediction error (MPE), the standard deviation of the prediction error (SDPE), the root mean square prediction error (RMSPE) and the prediction coefficient of determination $\left(R^{2}\right)$ measuring the strength of the linear relationship between predicted and observed values.

The second validation procedure was done following principles similar to $\mathrm{K}$-fold cross-validation, enabling us to perform what will be referred to in the following as external validation. $90 \%$ of the individuals was drawn randomly without replacement from the dataset and used as the training dataset. Validation was done on the remaining $10 \%$ of individuals (external validation). This procedure was repeated 1000 times, which provided robust results. External validation was used as a way to explore the predictive power of the resulting model for previously unseen data. In the following, the MPE, SDPE, RMSPE and $R^{2}$ indices, computed through this external validation, are adjoined the ext suffices (i.e. $\mathrm{MPE}_{\mathrm{ext}}, \mathrm{RMSPE}_{\mathrm{ext}}$ and so forth). Enclosing indices with the $<$ and $>$ signs indicates that the median value over the 1000 trials is given (for instance $<\mathrm{MPE}_{\mathrm{ext}}>$ ). $\mathrm{RMSPE}_{\mathrm{ext}}$ resulting from cross validation were also estimated as a function of SOC stocks values. This enabled us to refine the estimation of uncertainty related to the estimation of the spatial SOC stocks. The error on the SOC stock estimates for the whole territory was obtained by summing the errors on each elementary spatial unit:

$\Delta$ SOCstocks $=\sum_{j=1}^{m} \mathrm{~S}_{j} \mathrm{RMSPE}_{\left(\text {SOCstocks }_{j}\right)}$

where $\triangle \mathrm{SOC}$ stocks is the global error, $\mathrm{S}_{j}$ is the surface of the elementary spatial unit $j$, SOC $_{\text {stocks }}$ its estimated SOC stocks and RMSPE() the function relating the predicted SOC stocks to the model error (Eq. 2).

\subsubsection{Parameter settings for BRT models}

Although some general recommendations exist for setting the values for tree size, learning rate, minimum number of observations in the terminal nodes values and bag fraction, a tuning procedure was run, because, in practice, as for single regression trees, optimum values may depend on the dataset (Lilly et al., 2008). The $b f$ parameter was set to 0.75 and we tested different $t s, l r$, min.obs values, chosen according to recommendations found in the literature (Lilly et al., 2008; Ridgeway, 2006). This tuning procedure was carried out as in (Martin et al., 2009). The resulting parameter values are given in Table 1. 
Table 1. Tested and optimal values for the $t s, l r$, min.obs parameters of the three boosted regression trees models. The optimal values were selected as resulting in the best $<R^{2}$ ext $>$, obtained through the cross validation procedure

\begin{tabular}{llccc}
\hline Parameters & Tested values & \multicolumn{3}{c}{ Selected parameter value } \\
\cline { 3 - 5 } & & $\begin{array}{c}\mathrm{F} \\
\text { model }\end{array}$ & $\begin{array}{c}\text { Cult } \\
\text { model }\end{array}$ & $\begin{array}{c}\text { Extra } \\
\text { model }\end{array}$ \\
\hline$t s$ & $4,8,12$ & 8 & 8 & 12 \\
$l r$ & $0.001,0.005,0.01,0.1$ & 0.005 & 0.01 & 0.01 \\
min.obs & $4,6,8$ & 4 & 4 & 8 \\
\hline
\end{tabular}

Selecting these parameter settings for each of the models was a preliminary step in the study. We then assumed that these settings could be applied to all subsequent fits. They were thus used in turn for producing all the results displayed in the paper, i.e. regarding (i) the BRT models' performance on the full dataset and (ii) the predictive performance tested against independent data.

\section{Results}

\subsection{Observed SOC stocks}

The SOC stocks depended greatly on the land cover type (Fig. 2). Highest values were observed for the forest, grasslands and wetlands (though only two wetland observations). In the first $30 \mathrm{~cm}$, the stock in forest (median SOC stocks of $7.00 \mathrm{~kg} \mathrm{~m}^{-2}$ ) was less than under permanent grassland (median SOC stocks of $7.57 \mathrm{~kg} \mathrm{~m}^{-2}$ ) with comparable standard deviation (3.42 and $3.51 \mathrm{~kg} \mathrm{~m}^{-2}$, respectively). Dispersion of values on cultivated areas, excluding permanent grasslands was low $\left(1.85 \mathrm{~kg} \mathrm{~m}^{-2}\right)$ compared to permanent grasslands and forest lands. Lowest SOC stocks values were observed for vineyards (median SOC stocks of $3.2 \mathrm{~kg} \mathrm{~m}^{-2}$ ) and some uncultivated coastal areas (median SOC stocks of $2.42 \mathrm{~kg} \mathrm{~m}^{-2}$ ).

\subsection{Goodness of fit and predictive performance}

General indices of agreement of the models prediction and the observed data (MPE, SDPE, RMSPE, $R^{2}$ ), are given in Table 2. BRT models yielded good results when fitted on and validated against the full dataset (internal validation). The fit was best for the Cult model, with $R^{2}$ value of 0.91 and RMSPE value of $0.934 \mathrm{~kg} \mathrm{~m}^{-2}$. The prediction was poorer on forest soils, where the $\mathrm{F}$ model yielded 0.74 and $1.910 \mathrm{~kg} \mathrm{~m}^{-2}$ values for $R^{2}$ and RMSPE, respectively. For the three models, MPE was negligible indicating models with low precision and high accuracy. Ranking of model performance using cross-validation was the same as according to validation on the dataset used for learning. The Extra model, developed for prediction on soils under any kind of land use yielded $<R^{2}$ ext $>$ value of 0.5 (with $95 \%$ confidence interval of $[0.386,0.613])$ and $<\mathrm{RMSPE}_{\text {ext }}>$ of $2.271 \mathrm{~kg} \mathrm{~m}^{-2}\left(\mathrm{CI}_{95 \%}\right.$ of $\left.[1.862,2.68] \mathrm{kg} \mathrm{m}^{-2}\right) . \quad<\mathrm{MPE}_{\mathrm{ext}}>$ values, representing the bias, were on average low, if not negligible and reached $-0.002 \mathrm{~kg} \mathrm{~m}^{-2}$ for the Extra model. For this model, the $\mathrm{CI}_{95 \%}$ for $<\mathrm{MPE}_{\text {ext }}>$ was large $\left([-0.348,0.344] \mathrm{kg} \mathrm{m}^{-2}\right)$ indicating that some models, depending on the sub-dataset used for fitting produced significantly biased predictions on the sub-dataset used for validation. This model underestimated SOC stocks for low observed SOC stocks and overestimated SOC stocks for high observed values (Fig. 3). The best of the three models, when validated using crossvalidation was the Cult model, with a $<R^{2}$ ext $>$ value of 0.58 $([0.445,0.723])$ and $<\mathrm{RMSPE}_{\text {ext }}>$ of $1.94 \mathrm{~kg} \mathrm{~m}^{-2}([1.486$, 2.395] $\mathrm{kg} \mathrm{m}^{-2}$ ).

The analysis of the Extra model's error (Fig. 4) indicates a positive correlation between the observed $\mathrm{C}$ stock value and the $<$ RMSPE $_{\text {ext }}>$, estimated within C stock classes. Expected $<$ RMSPE $_{\text {ext }}>$ lies between 1 and $3 \mathrm{~kg} \mathrm{~m}^{-2}$ for SOC stocks belonging to the $[2,14] \mathrm{kg} \mathrm{m}^{-2}$ range. Uncertainty on the error estimate itself can be computed (Fig. 4), indicating $<$ RMSPE $_{\text {ext }}>$ values under $8 \mathrm{~kg} \mathrm{~m}^{-2}$ for SOC stocks below $15 \mathrm{~kg} \mathrm{~m}^{-2}$. Above this threshold, mean $<\mathrm{RMSPE}_{\text {ext }}>$, as well as the upper limit of the confidence interval rises indicating a very high uncertainty of the results in the model's prediction. CI95\% could not be computed above $18 \mathrm{~kg} \mathrm{~m}^{-2}$ because of the scarcity of such high observed values.

\subsection{Variable relative influence}

The computation of the VIM values associated with the predictors for the three models (Table 3 ) indicates a strong influence of clay content. This predictor ranks second for the Cult model and first for the F and Extra models. Rain is consistently ranked in the four most important predictors. For the Cult and Extra models, the land use appears to be important for predicting the SOC stocks. The fit of the Cult model showed that it is worth using a detailed description of the land use, since the $l u 2$ and $l u l$ predictors had a negligible importance, whereas the lu3 predictor had the most important VIM index. However, for the F model, the lu3 variable, which in this case represents the kind of forest considered, had a very low variable importance index. The VIM index value for rock fragments was more important for the $\mathrm{F}$ model than for the Cult model, and was ranked fourth. On the F model, the NPP values computed on each RMQS site ranked fifth. On the Cult and Extra models, the temperature, best represented by the transformed $a$ variable ranked 3 and 4, respectively. Temperature exhibited a limited importance for the F model, as did PET, whatever the model. 
Table 2. Fit and cross validation results for a ratio of $0.9 / 0.1$ training vs. validation datasets. Quality of the fit on the full data set is expressed using $R^{2}$, mean prediction error (MPE, $\mathrm{kg} \mathrm{m}^{-2}$ ), standard deviation of the prediction error (SDPE, $\mathrm{kg} \mathrm{m}^{-2}$ ), and root mean square prediction error (RMSPE, $\left.\mathrm{kg} \mathrm{m}^{-2}\right)$. The cross-validation results are expressed using $<R_{\text {ext }}^{2},<\mathrm{MPE}_{\text {ext }}>\left(\mathrm{kg} \mathrm{m}^{-2}\right),<\mathrm{SDPE}_{\mathrm{ext}}>\left(\mathrm{kg} \mathrm{m}^{-2}\right)$ and $<\mathrm{RMSPE}_{\text {ext }}>\left(\mathrm{kg} \mathrm{m}^{-2}\right)$ estimated using the validation datasets. The $95 \%$ confidence intervals obtained for the corresponding normal distributions using the standard percentile method are given in brackets.

\begin{tabular}{|c|c|c|c|c|c|c|c|c|c|c|c|c|}
\hline Model & $R^{2}$ & MPE & SDPE & RMSPE & & $<R_{\text {ext }}^{2}>$ & & $\mathrm{MPE}_{\text {ext }}>$ & & $\mathrm{SDPE}_{\text {ext }}>$ & & $\mathrm{MSPE}_{\text {ext }}>$ \\
\hline Cult & 0.91 & -0.001 & 0.935 & 0.934 & 0.58 & {$[0.445,0.723]$} & -0.041 & {$[-0.379,0.297]$} & 1.94 & {$[1.481,2.397]$} & 1.94 & {$[1.486,2.395]$} \\
\hline $\mathrm{F}$ & 0.74 & $2 \mathrm{e}-04$ & 1.912 & 1.910 & 0.36 & {$[0.141,0.57]$} & -0.009 & {$[-0.845,0.827]$} & 2.75 & {$[2.036,3.467]$} & 2.76 & {$[2.053,3.459]$} \\
\hline Extra & 0.73 & -0.001 & 1.727 & 1.727 & 0.5 & {$[0.386,0.613]$} & -0.002 & {$[-0.348,0.344]$} & 2.27 & {$[1.86,2.68]$} & 2.27 & {$[1.862,2.68]$} \\
\hline
\end{tabular}

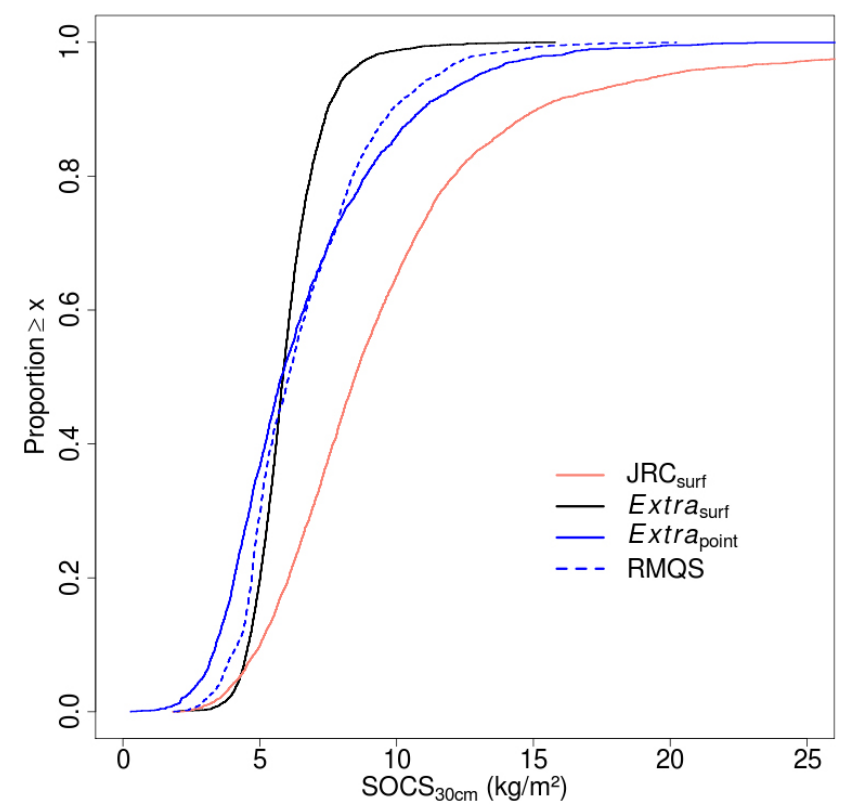

Fig. 3. Empirical cumulative distribution functions (ecdf) for the two spatial estimates presented in this paper (using the Extra model and the JRC estimate) as well as for the observed (curve RMQS) and

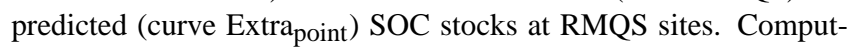
ing ecdf on spatial estimates is done as follows: first the statistical population is made of each spatial unit where the prediction model has been applied (the Extra model for instance). Second, a weight is computed for each unit as the ratio between its area and the sum of spatial units area (here, the area of France). Third, the ecdf is estimated on models predictions within the spatial units $\left(\mathrm{kg} \mathrm{m}^{-2}\right)$ using weights previously calculated. Ecdfs of site observed or predicted values are calculated using equal weights between individuals.

\subsection{Map of soil organic carbon stocks}

The total stock for France $(0-30 \mathrm{~cm})$ computed on the $12 \times 12 \mathrm{~km}^{2}$ grid was $3.242 \mathrm{PgC}$ for a surface of $541060 \mathrm{~km}^{2}$. The total surface represented by the grid is slightly smaller than the actual mainland French territory $\left(543965 \mathrm{~km}^{2}\right)$. The total stock for the French mainland territory could thus be rescaled to $3.260 \mathrm{PgC}$. Estimated uncertainty was

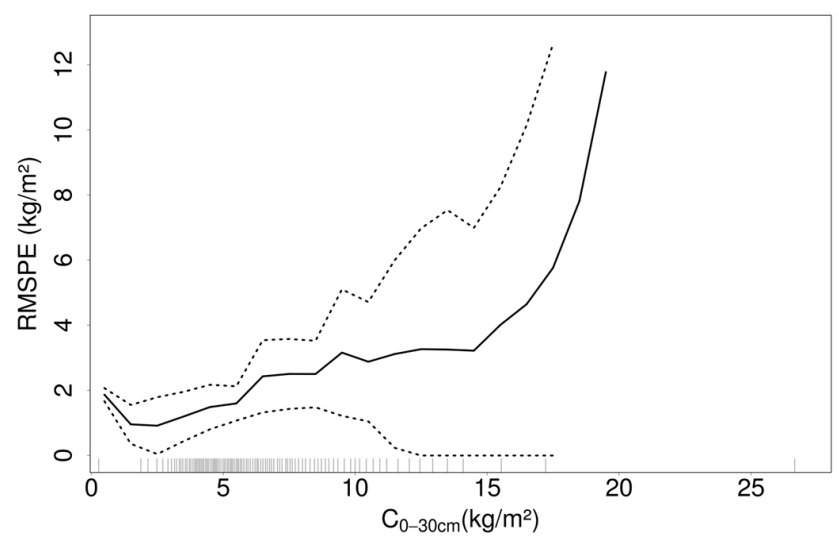

Fig. 4. Uncertainty of the Extra model, as a function of the organic carbon stock $(30 \mathrm{~cm})$. Uncertainty values (i.e. $<\mathrm{RMSPE}_{\mathrm{ext}}>$, resulting from cross-validations trials) are calculated as a function of predicted SOC stocks, grouped within intervals of $1 \mathrm{~kg} \mathrm{~m}^{-2}$ width, from 0 to $30 \mathrm{~kg} \mathrm{~m}^{-2}$. The solid line represents the mean of uncertainty within each interval of SOC stocks values, and the upper and lower dashed lines represent the bounds of the $\mathrm{CI}_{95 \%}$ assuming a normal distribution within each interval. Tick marks at the lower border of the diagram give the $1 \%$ quantiles for the RMQS dataset.

$0.872 \mathrm{PgC}$ (Eq. 2). Predicted SOC stocks ranged from 2.0 to $15.8 \mathrm{~kg} \mathrm{~m}^{-2}$ over the French territory. The highest stocks were observed in mountaineous areas (Alps, Jura, Massif Central and Pyrénées), in Brittany and in parts of Lorraine regions (Fig. 5).

The comparison of empirical cumulative distribution function (ecdf) between the observed SOC stocks on RMQS sites, and the surface estimate from the Extra model reveals several aspects of the spatial prediction quality (Fig. 3). It shows that although the Extra model managed to reproduce the distribution of the observed values, when applied to the whole territory, the resulting distribution exhibits a narrow range of predicted values. The variability on the predicted map was smaller than on observed or predicted SOC stocks values on RMQS sites, but the distributions were centered close to median values. 
Table 3. Relative influences of the predictors for each model, expressed as variable importance indexes (VIM), and rank according to the VIM values. The predictors are grouped, starting with the variables related to land use, then related to the climatic or pedoclimatic factors, then to plant productivity and finally related to the soil properties only. Variables names and definitions are detailed in Sects. 2.1.1 and 2.3.1.

\begin{tabular}{lrrrrrr}
\hline & \multicolumn{2}{c}{ Cult model } & \multicolumn{2}{c}{ F model } & \multicolumn{2}{c}{ Extra model } \\
\cline { 2 - 7 } Predictor & VIM & rank & VIM & rank & VIM & rank \\
\hline lu3 & 33.66 & 1 & 0.77 & 11 & - & - \\
lu2 & 1.26 & 13 & 0.00 & 14 & - & - \\
lu1 & 0.11 & 15 & - & - & - & - \\
lu_ipcc & 0 & 16 & - & - & 26.83 & 2 \\
a & 7.1 & 3 & 1.47 & 10 & 8.76 & 4 \\
$b$ & 3.72 & 7 & 4.83 & 7 & 6.53 & 6 \\
rain & 6.6 & 4 & 13.27 & 3 & 10.66 & 3 \\
pet & 3.3 & 8 & 4.4 & 8 & 5.73 & 7 \\
temp & 3.03 & 9 & 1.83 & 9 & 6.77 & 5 \\
npp & 2.89 & 10 & 6.54 & 5 & 5.33 & 8 \\
wlogging & 1.34 & 12 & 0.06 & 12 & - & - \\
wregime & 1.14 & 14 & 0.03 & 13 & - & - \\
rf & 6.08 & 5 & 8 & 4 & - & - \\
clay & 22.55 & 2 & 29.55 & 1 & 29.4 & 1 \\
silt & 1.96 & 11 & 5.91 & 6 & - & - \\
ph & 5.26 & 6 & 23.35 & 2 & - & - \\
\hline
\end{tabular}

\section{Discussion}

\subsection{Validity of the estimate}

The total SOC stocks estimate was in good agreement with a previous estimate $(3.1 \mathrm{PgC}$ on a soil mass equivalent to $30 \mathrm{~cm}$ under forest, Arrouays et al., 2001). However, it differs from the estimate based on the organic carbon content layer available at the European level (Jones et al., 2005) of 5.0 PgC for the first $30 \mathrm{~cm}$ (Hiederer, 2010). We recalculated this estimate by combining JRC's octop layer $(1 \mathrm{~km} \times 1 \mathrm{~km}$ resolution, Jones et al., 2005) and a spatial layer of bulk density $\left(10^{\prime} \times 10^{\prime}\right.$ grid, Smith et al., 2005) in topsoils $(0-$ $30 \mathrm{~cm}$ ). Adjusting the resolution of the octop and bulk density layers to the resolution of our $12 \mathrm{~km} \times 12 \mathrm{~km}$ grid was done using the ArcGIS zonal statistics algorithm for the SOC content and a weighted mean procedure for the bulk density layer. Our global estimate using these data layers was 5.303 PgC. This value lies outside the interval defined by taking into account the uncertainty associated with the BRT model $( \pm 0.872 \mathrm{PgC})$. The magnitude of the overestimation related to the JRC's European SOC content layer matched the one found by Dendoncker et al. (2008) at a much smaller scale for a small area of southern Belgium. Assuming that because of its systematic sampling scheme, the RMQS dataset is representative of the French territory,

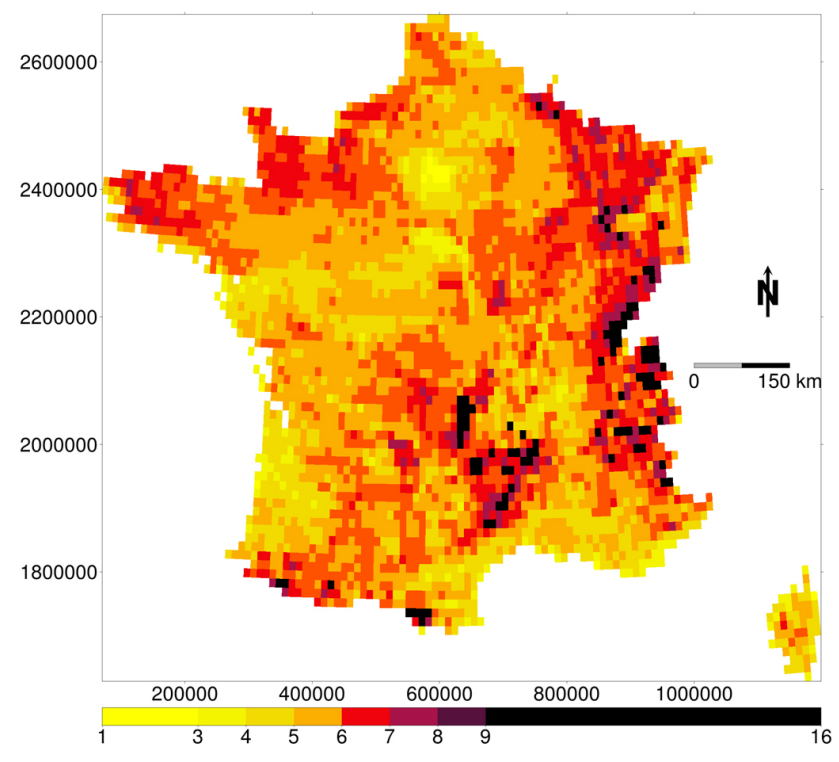

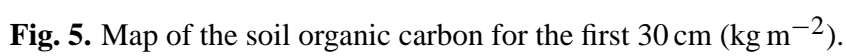

its cumulative distribution of SOC stocks can be used as a reference of SOC stocks in France. Figure 3 shows that the distribution resulting from the processing of JRC data consistently overestimated the SOC stocks. On the other hand, the Extra model spatial estimate was unbiased but the occurrence of high SOC values (above $8 \mathrm{~kg} \mathrm{~m}^{-2}$ ) was much lower than for the distribution on RMQS sites. This discrepancy was not observed for values below the SOC median value (circa $5 \mathrm{~kg} \mathrm{~m}^{-2}$ ). Thus the total estimated SOC stocks might underestimate the real SOC stocks for France but according to Fig. 3 the absolute error of the estimate provided here cannot explain the difference compared to the JRC data. The comparison between the empirical cumulative distribution function of observed RMQS SOC stocks, and the one provided by the Extra model, suggests that the distribution tails are poorly represented, i.e. that the extreme SOC stocks values where not predicted correctly by the model. This is likely to result from the spatial distribution of the predictors, since the model managed to predict extreme values when applied to the RMQS sites. The fact that there was a similar difference for clay (not shown here), the most important predictor in the Extra model, between the ecdf of the spatial layer and that of RMQS sites, supports this statement.

It can be argued that the resolution of the native datasets (especially for the SOC content layer of the JRC, $1 \mathrm{~km} \times 1 \mathrm{~km}$ ) is very different from the one presented in this paper. The aggregation of the data up to the $12 \mathrm{~km} \times 12 \mathrm{~km}^{2}$ may explain locally some of the differences with the estimate provided by the BRT model. However, at the national scale, i.e. when summing the SOC stocks over the whole map, the aggregation itself is not expected to explain much of the difference observed here. More likely, the difference between estimates comes from SOC and bulk density estimates 
themselves. The JRC SOC content estimate results from pedotransfer rules fitted on the European soil database (at a scale of 1:1000000) and validated on England, Wales and Italy only. Bulk densities have been estimated using pedotransfer rules as well. The estimation presented here, on the other hand, relies on a model fitted and validated against a systematic sampling scheme $(16 \mathrm{~km} \times 16 \mathrm{~km}$ resolution $)$ with both SOC content and bulk density measurements.

$\mathrm{CO}_{2}$ emissions from soils are often modelled as a function of the product between the current SOC stocks and mineralization rates (as in the RothC model). As a result, simulating $\mathrm{CO}_{2}$ emissions for France under diverse scenarios can potentially result in very different estimates of emissions, depending upon whether the baseline SOC stock is considered to be $3.260 \mathrm{PgC}$ or $5.303 \mathrm{PgC}$. Consequently, studies estimating SOC changes at the national scale, such as in Smith et al. (2005) or Zaehle et al. (2007), could benefit from improvements of SOC distribution estimates, through the use of data from soil monitoring networks (SMNs).

SMNs can help refine estimates of SOC dynamics too by providing better starting soil $\mathrm{C}$ values for model initialisation, and for testing models against measured change in SOC. Conversely, the performance of SMNs themselves, for detecting long term SOC change trend has recently been demonstrated (Saby et al., 2008b), using estimates of SOC spatial distributions (in that case the JRC's SOC content map, Hiederer et al., 2004). Thus, more accurate estimates of SOC distributions could in turn improve the assessment of the performance of SMNs.

The uncertainty estimated for the BRT model arises from the application of the uncertainty function depending on SOC stock values provided by the cross validation trials (Fig. 4). The fitted model is characterized by very high uncertainties for SOC stocks values above $15 \mathrm{~kg} \mathrm{~m}^{-2}$. Uncertainty on this estimate itself starts to increase notably from $11 \mathrm{~kg} \mathrm{~m}^{-2}$, making it difficult to draw any conclusion about the validity of the model for such SOC stocks values. On the other hand, for values under $11 \mathrm{~kg} \mathrm{~m}^{-2}$, the value of the uncertainty of predicted SOC stocks values is accurately known. The model error $\left(<\mathrm{RMSPE}_{\mathrm{ext}}>\right.$ ) is comparable to results of other study studies based on different statistical techniques, but is among the few providing an assessment of model predictions based on cross-validation. Different geostatistical models yielded a estimate of $4.54 \pm 0.74 \mathrm{PgC}$ for Laos (Phachomphon et al., 2010) and a RMSE of $2.89 \mathrm{~kg} \mathrm{~m}^{-2}$ when mapping 0-50 $\mathrm{cm}$ SOC stocks for the Indiana state (Mishra et al., 2009). The quality of the fit was better than for recent studies applying generalized linear models to the prediction of SOC stocks in Tibetan grasslands and explaining $73 \%$ of the variation of SOC densities (Yang et al., 2008), to be compared to the $R^{2}$ of 73, 74 and $91 \%$ of the Extra, $\mathrm{F}$ and Cult models presented here. On the RMQS dataset, the SOC stock values above $15 \mathrm{~kg} \mathrm{~m}^{-2}$, which could be considered outside the validity domain of the BRT model are rare (2\% of the RMQS sites display SOC stocks values above $15 \mathrm{~kg} \mathrm{~m}^{-2}$, Fig. 3). The predicted distribution of SOC stocks includes a negligible fraction of SOC stocks above $15 \mathrm{~kg} \mathrm{~m}^{-2}$ (below $0.01 \%$ ), and consequently such spatial units, where estimated uncertainty is high, have a negligible impact on the global uncertainty related to the national SOC stocks prediction $(0.14 \%)$.

\subsection{Relative importance of the predictors}

\subsubsection{Effect of the land use}

Discrepancies between the Cult and the F models might give an estimate on how agricultural practices, both in grassland and arable lands, determine the relationships between pedoclimatic variables and SOC stocks, compared to forest systems. For instance, the lesser importance of soil $\mathrm{pH}$ for the Cult model might have resulted from the influence of some agricultural practices onto this chemical parameter. Similarly, it was possible to demonstrate that the effect of clay depended on the land use and was attenuated for croplands (not shown here). This might be explained by the fact that farmers have, for crop cultivation for instance, the chance of mitigating the influence of an unfavourable water budget, related to low clay contents, by tuning the cultivation calendar or the irrigation timing. More generally, the F model performed much worse than the Cult model $\left(R^{2}\right.$ ext are 0.36 and 0.58 , respectively). This means that the SOC stocks under forest have high variability, that remained unexplained by the set of variables that were included in the model. The VIMs of predictors related to the land use showed that if, in some case, a detailed land use description is relevant (predictor $l u 3$ in model Cult), a coarser description (i.e. lu_ipcc in model Extra) is still valuable for predicting SOC stocks, and of the same importance as information about the clay content (Table 3).

\subsubsection{Effect of the soil properties}

The modelled effect of clay on SOC stocks increased monotonically (Fig. 6a). This expected effect may result from several processes. The most commonly cited is the physical interaction, mediated by various soil elements and biological activity, between the clay materials and organic compounds (Arrouays et al., 2006; Chaplot et al., 2009). It tends to protect soil organic matter (SOM) from decomposition (Liao et al., 2009). The modelled SOC response to clay content may include other processes such as the influence of clay on the soil's moisture regimes via its influence on the water holding capacity (Wosten et al., 1999).

The soil moisture has been reported, both in field experiments and on large scale statistical surveys (Bauer et al., 2008; Meersmans et al., 2008), to influence the SOM decomposition and consequently the observed SOC stocks. The modelling of soil moisture regimes, as it is done within the RothC model (predictor $b$ ), was not, on average, relevant for our dataset, and was of much less importance than variables 

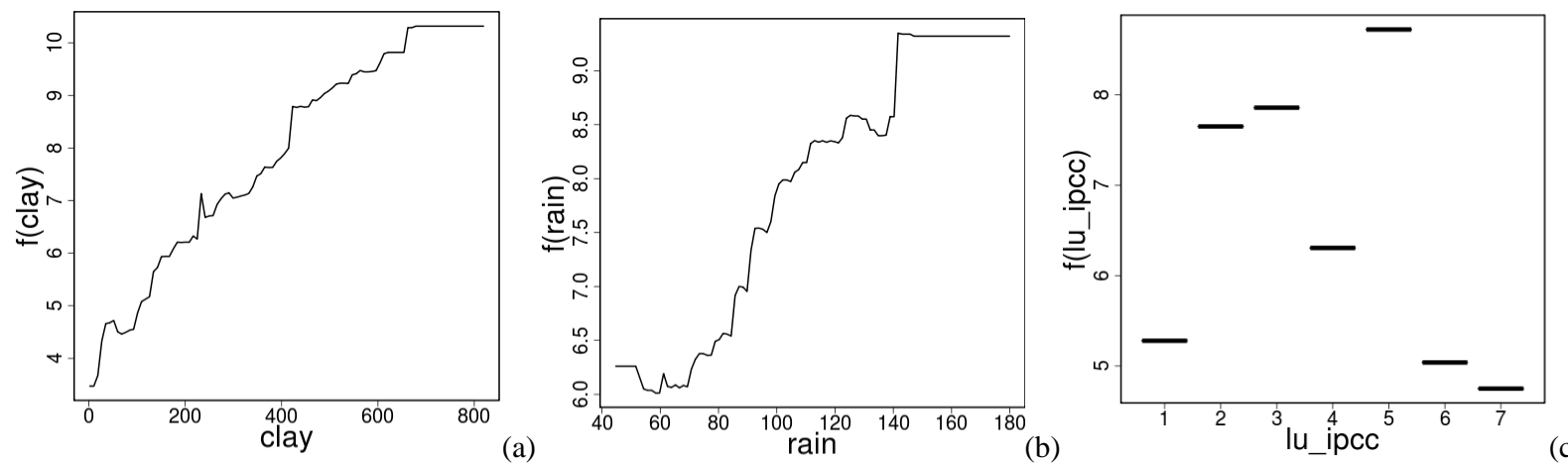

Fig. 6. Effect of the three most important variables in the Extra model (i.e. (a) clay, (b) rain and (c) lu_ipcc). The lu_ipcc variable is coded using the adapted IPCC classification: croplands (1), permanent grasslands (2), woodlands (3) orchards, shrubby perennial crops (4), wetlands (5), others (6), vineyards (7).

such as rain or clay alone (Table 3). Surprisingly, the inclusion of water content variables (wlogging and wregime) resulting from field observations, did not have much influence on SOC stocks. There may be several reasons for this, mainly arising from the available dataset. In many cases (25\%) this information was missing, which decreases the final VIM of this variable in the fitted models. Secondly, the water regime was available at the whole profile level only, and might not have been representative of the first $30 \mathrm{~cm}$. Thirdly, this water regime was based on the observation at the sampling time, and, again, might not have been representative of the water regime across the year.

\subsubsection{Effect of the climatic variables}

The relationship between climatic variables and amount of organic carbon in soil is also well known, and again, is linked to the effect of these variables on plant productivity on one side, and soil carbon decomposition on the other. The effect of these variables, as they are measured here (rain, PET, above ground temperature), is mediated by soil properties and the vegetation cover. As such, the rain predictor was consistently one of the most important. The effect of temperature (predictors temp and $a$ ), which may be dependent upon other variables such as physical protection, chemical protection, drought, flooding and freezing (Davidson et al., 2000), was important too, but less than the effect of the rainfall. Temperature increase enhance NPP and mineralization at the same time (Heimann and Reichstein, 2008), assuming that temperature remains below a given threshold. The tradeoff between mineralization and NPP increase determines the sign of relationship between SOC stocks and temperature. Here, the relationship between SOC stocks and $a$ decreased monotonically (not shown here), which could indicate that the effect of temperature on mineralisation is, in France, more important than the effect onto NPP.

\subsection{Possible improvements of the models}

From the current models of SOC dynamics, the influence of decomposition modifiers (here $a, b$ ) is expected to be of same magnitude as the estimated soil carbon inputs (Martin et al., 2009). However, our estimate of carbon inputs, the npp variable, had a low VIM value. This demonstrated that our estimate was inaccurate. Both the resolution of the MODIS data and algorithms used for providing NPP, and our procedure for retrieving values at our sampling locations might have resulted in an irrelevant NPP predictor. Additional work would be necessary for estimating more accurately SOC inputs on the RMQS sites.

Topography was not taken into account in this study. Indeed it has been shown that it is relevant for predicting SOC stocks. Importance of variables derived from Digital Elevation Models has been demonstrated at the national (Chaplot et al., 2009) and small region scale (Grimm et al., 2008). This might be related to redistribution processes related to soil erosion, for instance. In our case this information was not readily available, either at the RMQS sites locations, or at the national scale, and thus was not included in the models.

$\mathrm{Fe}$ and $\mathrm{Al}$ oxides and CEC are also known for being correlated to SOC stocks (Chaplot et al., 2009). Although this information was available alongside SOC stocks measurements at RMQS sites, this information cannot be used as an external variable determining SOC stocks, because these soil properties, and mainly CEC, are not as well known, as are SOC stocks. Consequently their use for predicting the spatial distribution of SOC stocks is limited.

The best candidate among soil properties would be the soil $\mathrm{pH}$. The spatial distribution at a national scale of this predictor, relevant for forest soils, will be accessible in a near future. Its omission in the Extra model led to some discrepancies between known SOC stocks distribution and the modelled one. For instance, the model predicted low SOC stocks in the Landes region (south west of France), most probably because of low clay contents, whereas acid forest soils in this 
region are known for exhibiting higher SOC stocks values, between 8 and $14 \mathrm{~kg} \mathrm{~m}^{-2}$ (Jolivet et al., 2003).

The influence of land management and agricultural practices on SOC stocks has been, and still is widely studied, and its role might in some cases be underestimated (Bell and Worrall, 2009). It is well established that some specific practices, such as organic matter addition (Lashermes et al., 2009), reduced tillage practices (Metay et al., 2009) or crop residues management and permanent cover crops (Rice, 2006), can influence SOC input and its fate in agricultural soils. Without considering specific agricultural practices, the inclusion of information about detailed land use proved to be valuable for explaining observed SOC stocks: the VIM value of the $l u 3$ variable greatly outperformed those of the $l u 2$ and $l u l$ variables, which are less informative about the land use. The inclusion of the $l u 3$ variable in the model used for estimating SOC stocks at the national scale was not possible since spatial information with this level of detail was not available. Obtaining such information is needed in order to refine our estimate of the spatial distribution of SOC stocks in French soils. Similarly, it could support detailed implementation of future land use changes and the consequences of these for SOC dynamics.

\section{Conclusions}

In this paper we provide a new estimate for the spatial distribution of SOC stocks in the top $30 \mathrm{~cm}$ of soils in France, based on the French monitoring network (RMQS). The total estimate is $3.260 \pm 0.872 \mathrm{PgC}$. It was compared to another estimate based on the previously published European octop maps. This second estimate was $5.303 \mathrm{PgC}$, consistent with the SOC stocks published by the JRC for European countries, and much higher than the estimate provided here, based on RMQS data. Two elements advocate the preferential use of the estimate presented here. First, it relies on a dataset provided by a sampling scheme ensuring an efficient treatment of the spatial variability of SOC, both locally (through composite sampling) and of over a larger extent (through the use of a regular $16 \times 16 \mathrm{~km}^{2}$ grid). The RMQS sampling protocol is also one of the few, at the European level, providing bulk densities. This avoids the need to use pedo-transfer functions for estimating bulk density, and the uncertainties associated with such estimates. Second, the proposed model relied on the use of BRT which has been confirmed here as being a robust tools for predicting SOC stocks. While offering a good predictive performance, it enabled quantification of relationships between SOC stocks and pedo-climatic variables (plus their interactions) over the French territory. These relationships strongly depended on the land use, and more specifically differed between forest soils and cultivated soil. Along with land use, the clay content of soils was the most important driving variable of SOC stocks. In addition to improvement of the model by including more predictors, the refinement of spatial data layers of soil and land use will be a critical step for improving SOC stocks assessments at the country level.

Acknowledgements. The sampling and soil analyses were supported by a French Scientific Group of Interest on soils: the GIS Sol, involving the French Ministry for Ecology, Energy, Sustainable Development and Land Use (MEEDDAT), the French Ministry of Agriculture (MAP), the French Agency for Environment and Energy Management (ADEME), the Institute for Research and Development (IRD), the National Forest Inventory (IFN) and the National Institute for Agronomic Research (INRA). The authors thank all the soil surveyors and technical assistants involved in sampling the sites. Special thanks are addressed to the technical assistants from the National French Soil Bank for sample handling and preparation. Pete Smith is a Royal Society-Wolfson Research Merit Award holder.

Edited by: J. Leifeld

\section{References}

Arrouays, D., Deslais, W., and Badeau, V.: The carbon content of topsoil and its geographical distribution in France, Soil Use Manage., 17, 7-11, 2001.

Arrouays, D., Jolivet, C., Boulonne, L., Bodineau, G., Saby, N., and Grolleau, E.: A new initiative in France: a multi-institutional soil quality monitoring network, Comptes rendus de l'Academie d'Agriculture de France, 88, 93-105, 2002.

Arrouays, D., Saby, N., Walter, C., Lemercier, B., and Schvartz, C.: Relationships between particle-size distribution and organic carbon in French arable topsoils, Soil Use Manage., 22, 48-51, 2006.

Batjes, N. H.: Total carbon and nitrogen in the soils of the world, Eur. J. Soil Sci., 47, 151-163, 1996.

Bauer, J., Herbst, M., Huisman, J. A., Weihermuller, L., and Vereecken, H.: Sensitivity of simulated soil heterotrophic respiration to temperature and moisture reduction functions, Geoderma, 145, 17-27, 2008.

Bell, M. J. and Worrall, F.: Estimating a region's soil organic carbon baseline: the undervalued role of land-management, Geoderma, 152(1-2), 74-84, 2009.

Bellamy, P. H., Loveland, P. J., Bradley, R. I., Lark, R. M., and Kirk, G. J. D.: Carbon losses from all soils across England and Wales 1978-2003, Nature, 437, 245-248, 2005.

Breiman, L., Friedman, J. H., Olshen, R. A., and Stone, C. J.: Classification and regression trees, Wadsworth, Inc. Monterey, Calif., U.S.A., 368 pp., 1984.

Bui, E., Henderson, B., and Viergever, K.: Using knowledge discovery with data mining from the australian soil resource information system database to inform soil carbon mapping in australia, Global Biogeochem. Cy., 23, GB4033, doi:10.1029/2009GB003506, 2009.

Chakir, R. and Parent, O.: Determinants of land use changes: A spatial multinomial probit approach, Pap. Reg. Sci., 88, 327-344, 2009.

Chaplot, V., Bouahom, B., and Valentin, C.: Soil organic carbon stocks in Laos: spatial variations and controlling factors, Glob. Change Biol., 16, 1380-1393, 2009. 
Coleman, K., Jenkinson, D. S., Crocker, G. J., Grace, P. R., Klir, J., Korschens, M., Poulton, P. R., and Richter, D. D.: Simulating trends in soil organic carbon in long-term experiments using RothC-26.3, Geoderma, 81, 29-44, 1997.

Davidson, E. A., Trumbore, S. E., and Amundson, R.: Soil warming and organic carbon content, Nature, 408, 789-790, 2000.

Dendoncker, N., van Wesemael, B., Smith, P., Lettens, S., Roelandt, C., and Rounsevell, M.: Assessing scale effects on modelled soil organic carbon contents as a result of land use change in Belgium, Soil Use Manage., 24, 8-18, 2008.

Elith, J., Leathwick, J. R., and Hastie, T.: A working guide to boosted regression trees, J. Anim. Ecol., 77, 802-813, 2008.

Eswaran, H., Vandenberg, E., and Reich, P.: Organic-carbon in soils of the world, Soil Sci. Soc. Am. J., 57, 192-194, 1993.

Feranec, J., Jaffrain, G., Soukup, T., and Hazeu, G.: Determining changes and flows in European landscapes 1990-2000 using Corine land cover data, Appl. Geogr., 30, 19-35, 2010.

Freund, Y. and Schapire, R. E.: Experiments with a New Boosting Algorithm, in: Machine Learning: Proceedings of the Thirteenth International Conference, Morgan Kauffman, San Francisco, 148-156, 1996.

Friedman, J. H.: Greedy function approximation: A gradient boosting machine, Ann. Stat., 29, 1189-1232, 2001.

Friedman, J. H. and Meulman, J. J.: Multiple additive regression trees with application in epidemiology, Stat. Med., 22, 13651381, 2003.

Grimm, R., Behrens, T., Marker, M., and Elsenbeer, H.: Soil organic carbon concentrations and stocks on Barro Colorado Island - Digital soil mapping using Random Forests analysis, Geoderma, 146, 102-113, 2008.

Hastie, T., Tibshirani, R., and Friedman, J.: The Elements of Statistical Learning, Data Mining, Inference, and Prediction, Second Edition, Springer Series in Statistics, 746 pp., 2001.

Heimann, M. and Reichstein, M.: Terrestrial ecosystem carbon dynamics and climate feedbacks, Nature, 451, 289-292, 2008.

Hiederer, R.: Organic carbon per country, http://eusoils.jrc.ec. europa.eu/ESDB_Archive/octop/Resources/OC_Per_Country. pdf, access: 5 November 2010.

Hiederer, R., Jones, R. J. A., and Montanarella, L.: Topsoil Organic Carbon Content in Europe, Special publication No. SP.I.04.72, map in ISO B1 format, European Communities, Joint Research Centre, Ispra, Italy, 2004.

ISSS-ISRIC-FAO: World Reference Base for Soil Resources, World Soil Resources Reports 84, Tech. rep., Fao, Rome, 91 pp., 1998.

Jolivet, C., Arrouays, D., Leveque, J., Andreux, F., and Chenu, C.: Organic carbon dynamics in soil particle-size separates of sandy Spodosols when forest is cleared for maize cropping, Eur. J. Soil Sci., 54, 257-268, 2003.

Jones, R. J. A., Hiederer, R., Rusco, E., and Montanarella, L.: Estimating organic carbon in the soils of Europe for policy support, Eur. J. Soil Sci., 56, 655-671, 2005.

Krogh, L., Noergaard, A., Hermansen, M., Greve, M. H., Balstroem, T., and Breuning-Madsen, H.: Preliminary estimates of contemporary soil organic carbon stocks in Denmark using multiple datasets and four scaling-up methods, Agr. Ecosyst. Environ., 96, 19-28, 2003.

Lal, R.: Soil carbon sequestration to mitigate climate change, Geoderma, 123, 1-22, 2004.

Lashermes, G., Nicolardot, B., Parnaudeau, V., Thuries, L., Chaus- sod, R., Guillotin, M. L., Lineres, M., Mary, B., Metzger, L., Morvan, T., Tricaud, A., Villette, C., and Houot, S.: Indicator of potential residual carbon in soils after exogenous organic matter application, Eur. J. Soil. Sci., 60, 297-310, 2009.

Lawrence, R., Bunn, A., Powell, S., and Zambon, M.: Classification of remotely sensed imagery using stochastic gradient boosting as a refinement of classification tree analysis, Remote Sens. Environ., 90, 331-336, 2004.

Liao, Q. L., Zhang, X. H., Li, Z. P., Pan, G. X., Smith, P., Jin, Y., and Wu, X. M.: Increase in soil organic carbon stock over the last two decades in China's Jiangsu Province, Glob. Change Biol., 15, 861-875, 2009.

Lilly, A., Nemes, A., Rawls, W. J., and Pachepsky, Y. A.: Probabilistic approach to the identification of input variables to estimate hydraulic conductivity, Soil Sci. Soc. Am. J., 72, 16-24, 2008.

Lo Seen, D., Ramesh, B. R., Nair, K. M., Martin, M., Arrouays, D., and Bourgeon, G.: Soil carbon stocks, deforestation and landcover changes in the Western Ghats biodiversity hotspot (India), Glob. Change Biol., 16, 1777-1792, 2010.

Martin, M. P., Lo Seen, D., Boulonne, L., Jolivet, C., Nair, K. M., Bourgeon, G., and Arrouays, D.: Optimizing pedotransfer functions for estimating soil bulk density using boosted regression trees, Soil Sci. Soc. Am. J., 73, 485-493, 2009.

Meersmans, J., De Ridder, F., Canters, F., De Baets, S., and Van Molle, M.: A multiple regression approach to assess the spatial distribution of Soil Organic Carbon (Soc) at the regional scale (Flanders, Belgium), Geoderma, 143, 1-13, 2008.

Metay, A., Mary, B., Arrouays, D., Labreuche, J., Martin, M., Nicolardot, B., and Germon, J. C.: Effects of reduced or no tillage practices on $\mathrm{C}$ sequestration in soils in temperate regions, Can. J. Soil. Sci., 89, 623-634, 2009.

Mishra, U., Lal, R., Slater, B., Calhoun, F., Liu, D. S., and Van Meirvenne, M.: Predicting Soil Organic Carbon Stock Using Profile Depth Distribution Functions and Ordinary Kriging, Soil Sci. Soc. Am. J., 73, 614-621, 2009.

Morvan, X., Saby, N. P. A., Arrouays, D., Le Bas, C., Jones, R. J. A., Verheijen, F. G. A., Bellamy, P. H., Stephens, M., and Kibblewhite, M. G.: Soil monitoring in Europe: A review of existing systems and requirements for harmonisation, Sci. Total Environ., 391, 1-12, 2008.

Paustian, K., Andren, O., Janzen, H. H., Lal, R., Smith, P., Tian, G., Tiessen, H., Van Noordwijk, M., and Woomer, P. L.: Agricultural soils as a sink to mitigate $\mathrm{CO}_{2}$ emissions, Soil Use Manage., 13, 230-244, 1997.

Phachomphon, K., Dlamini, P., and Chaplot, V.: Estimating carbon stocks at a regional level using soil information and easily accessible auxiliary variables, Geoderma, 155, 372-380, 2010.

Post, W. M., Emanuel, W. R., Zinke, P. J., and Stangenberger, A. G.: Soil carbon pools and world life zones, Nature, 298, 156-159, 1982.

Quintana-Segui, P., Le Moigne, P., Durand, Y., Martin, E., Habets, F., Baillon, M., Canellas, C., Franchisteguy, L., and Morel, S.: Analysis of near-surface atmospheric variables: Validation of the Safran analysis over France, J. Appl. Meteorol. Clim., 47, 92 107, 2008.

Rice, C. W.: Introduction to special section on greenhouse gases and carbon sequestration in agriculture and forestry, J. Environ. Qual., 35, 1338-1340, 2006. 
Ridgeway, G.: gbm: Geberalized Boosted regression Models. R package version 1.5-7., 2006

Running, S. W., Nemani, R. R., Heinsch, F. A., Zhao, M. S., Reeves, M., and Hashimoto, H.: A continuous satellite-derived measure of global terrestrial primary production, Bioscience, 54, 547$560,2004$.

Saby, N. P. A., Arrouays, D., Antoni, V., Lemercier, B., Follain, S., Walter, C., and Schvartz, C.: Changes in soil organic carbon in a mountainous French region, 1990-2004, Soil Use Manage., 24, 254-262, 2008a.

Saby, N. P. A., Bellamy, P. H., Morvan, X., Arrouays, D., Jones, R. J. A., Verheijen, F. G. A., Kibblewhite, M. G., Verdoodt, A., Uveges, J. B., Freudenschuss, A., and Simota, C.: Will European soil-monitoring networks be able to detect changes in topsoil organic carbon content?, Glob. Change Biol., 14, 2432-2442, 2008 b.

Schlesinger, W. H.: Biogeochemistry: an analysis of global change, Academic Press, San Diego Usa, 443 pp., 1991.

Schnebelen, N., Nicoullaud, B., Bourennane, H., Couturier, A., Verbeque, B., Revalier, C., Bruand, A., and Ledoux, E.: The Stics model to predict nitrate leaching following agricultural practices, Agronomie, 24, 423-435, 2004.

Smith, J., Smith, P., Wattenbach, M., Zaehle, S., Hiederer, R., Jones, R. J. A., Montanarella, L., Rounsevell, M. D. A., Reginster, I., and Ewert, F.: Projected changes in mineral soil carbon of European croplands and grasslands, 1990-2080, Glob. Change Biol., 11, 2141-2152, 2005.

Tomlinson, R. W. and Milne, R. M.: Soil carbon stocks and land cover in northern ireland from 1939 to 2000, Appl. Geogr., 26 (1), 18-39, 2006.
Tornquist, C. G., Giasson, E., Mielniczuk, J., Cerri, C. E. P., and Bernoux, M.: Soil organic carbon stocks of rio grande do sul, brazil, Soil Sci. Soc. Am. J., 73(3), 975-982, 2009.

van Wesemael, B., Paustian, K., Meersmans, J., Goidts, E., Barancikova, G., and Easter, M.: Agricultural management explains historic changes in regional s oil carbon stocks, P. Natl. Acad. Sci. USA, 107(33), 14926-14930, 2010.

Wosten, J. H. M., Lilly, A., Nemes, A., and Le Bas, C.: Development and use of a database of hydraulic properties of European soils, Geoderma, 90, 169-185, 1999.

Yang, Y. H., Fang, J. Y., Tang, Y. H., Ji, C. J., Zheng, C. Y., He, J. S., and Zhu, B. A.: Storage, patterns and controls of soil organic carbon in the Tibetan grasslands, Glob. Change Biol., 14, 1592 1599, 2008.

Yokozawa, M., Shirato, Y., Sakamoto, T., Yonemura, S., Nakai, M., and Ohkura, T.: Use of the RothC model to estimate the carbon sequestration potential of organic matter application in Japanese arable soils, Soil Sci. Plant Nutr., 56, 168-176, 2010.

Yu, D. S., Shi, X. Z., Wang, H. J., Sun, W. X., Warner, E. D., and Liu, Q. H.: National scale analysis of soil organic carbon storage in china based on chinese soil taxonomy, Pedosphere, 17(1), 1118, 2007.

Zaehle, S., Bondeau, A., Carter, T. R., Cramer, W., Erhard, M. Prentice, I. C., Reginster, I., Rounsevell, M. D. A., Sitch, S., Smith, B., Smith, P. C., and Sykes, M.: Projected changes in terrestrial carbon storage in Europe under climate and land-use change, 1990-2100, Ecosystems, 10, 380-401, 2007. 